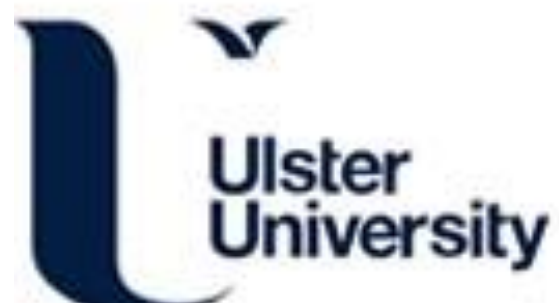

Red Mud-Reduced Graphene Oxide Nanocomposites for the Electrochemical Sensing of Arsenic

Deshmukh, S., Banerjee, D., Bhattacharya, G., Fishlock, S., Barman, A., McLaughlin, J., \& Roy, S. S. (2020).

Red Mud-Reduced Graphene Oxide Nanocomposites for the Electrochemical Sensing of Arsenic. ACS Applied Nano Materials, 3(5), 4084-4090. https://doi.org/10.1021/acsanm.0c00165

Link to publication record in Ulster University Research Portal

Published in:

ACS Applied Nano Materials

Publication Status:

Published (in print/issue): 22/05/2020

DOI:

10.1021/acsanm.0c00165

Document Version

Author Accepted version

\section{General rights}

Copyright for the publications made accessible via Ulster University's Research Portal is retained by the author(s) and / or other copyright owners and it is a condition of accessing these publications that users recognise and abide by the legal requirements associated with these rights.

\section{Take down policy}

The Research Portal is Ulster University's institutional repository that provides access to Ulster's research outputs. Every effort has been made to ensure that content in the Research Portal does not infringe any person's rights, or applicable UK laws. If you discover content in the Research Portal that you believe breaches copyright or violates any law, please contact pure-support@ulster.ac.uk. 


\section{ACS APPLIED NANO MATERIALSUULSTER}

\section{Article}

\section{Red Mud-Reduced Graphene Oxide Nanocomposites for the Electrochemical Sensing of Arsenic}

Sujit Deshmukh, Debosmita Banerjee, Gourav Bhattacharya, Sam J.

Fishlock, Anjan Barman, James A. McLaughlin, and Susanta Sinha Roy

ACS Appl. Nano Mater., Just Accepted Manuscript • DOI: 10.1021/acsanm.0c00165 • Publication Date (Web): 10 Apr 2020

Downloaded from pubs.acs.org on April 24, 2020

\section{Just Accepted}

"Just Accepted" manuscripts have been peer-reviewed and accepted for publication. They are posted online prior to technical editing, formatting for publication and author proofing. The American Chemical Society provides "Just Accepted" as a service to the research community to expedite the dissemination of scientific material as soon as possible after acceptance. "Just Accepted" manuscripts appear in full in PDF format accompanied by an HTML abstract. "Just Accepted" manuscripts have been fully peer reviewed, but should not be considered the official version of record. They are citable by the Digital Object Identifier (DOI®). "Just Accepted" is an optional service offered to authors. Therefore, the "Just Accepted" Web site may not include all articles that will be published in the journal. After a manuscript is technically edited and formatted, it will be removed from the "Just Accepted" Web site and published as an ASAP article. Note that technical editing may introduce minor changes to the manuscript text and/or graphics which could affect content, and all legal disclaimers and ethical guidelines that apply to the journal pertain. ACS cannot be held responsible for errors or consequences arising from the use of information contained in these "Just Accepted" manuscripts. 


\title{
Red Mud-Reduced Graphene Oxide Nanocomposites for the Electrochemical 2 Sensing of Arsenic
}

\author{
3 Sujit Deshmukh ${ }^{\dagger}$, Debosmita Banerjee ${ }^{\dagger}$, Gourav Bhattacharya ${ }^{\ddagger}$, Sam J. Fishlock ${ }^{\star}$, Anjan Barman§, James \\ $4 \quad$ McLaughlin*, Susanta Sinha Roy ${ }^{\dagger *}$ \\ 5 Department of Physics, School of Natural Sciences, Shiv Nadar University, NH-91, Uttar Pradesh 201314, India. \\ 6 Nanotechnology and Integrated Bioengineering Centre, University of Ulster, Jordanstown Campus, Newtownabbey, \\ 7 BT37 0QB, Northern Ireland, UK. \\ 8 \$Department of Condensed Matter Physics and Material Sciences, S. N. Bose National Centre, Block JD, Sector III, \\ 9 Salt Lake, Kolkata 700098, India.
}

\section{ABSTRACT}

This work demonstrates the applicability of red mud-reduced graphene oxide (RM-rGO) nanocomposites, for the reliable and selective electrochemical detection of arsenic. The new nanocomposite material shows excellent anti-interference activity towards the arsenic ions $\left(\mathrm{As}^{3+}\right)$ with the co-occurrence of other common cations $\left(\mathrm{Cd}^{2+}, \mathrm{Cr}^{2+}, \mathrm{Zn}^{2+}, \mathrm{Pb}^{2+}\right.$, and $\left.\mathrm{Hg}^{2+}\right)$. Especially, the nanocomposite is exceptionally selective for $\mathrm{As}^{3+}$ in the presence of $\mathrm{Cu}^{2+}$ ions, which is stated to be the main interfering agent in the electrochemical detection of $\mathrm{As}^{3+}$. Under optimal experimental conditions, the new nanocomposite displays a high sensitivity $(2.49 \mu \mathrm{A} / \mathrm{ppb})$ as well as a very low detection limit $(0.07 \mathrm{ppb})$ towards $\mathrm{As}^{3+}$ detection. This excellent electrochemical performance of the composite is accounted for the high adsorption proficiency of hematite $\left(\mathrm{Fe}_{2} \mathrm{O}_{3}\right)$ phase rich nano red mud particles and enhanced electron transfer kinetics due to the presence of rGO.

KEYWORDS: Red mud, arsenic, hematite, electrochemical detection, sensitivity, electron transfer kinetics.

\section{INTRODUCTION}

Arsenic ion $\left(\mathrm{As}^{3+}\right)$, a highly toxic substance, widely distributed in nature and one of the most abundant mineral in the earth's crust. ${ }^{12}$ According to the World Health Organization (WHO), the maximum acceptable level of $\mathrm{As}^{3+}$ in drinking water is $10 \mathrm{ppb}$ and around 20 countries are suffering from serious $\mathrm{As}^{3+}$ contamination. ${ }^{3}$ The determination of trace level (sub ppb) of $\mathrm{As}^{3+}$ in natural water (ocean, sea, rivers), wastewater (from mining, metal processing, pesticides, organic 
1 chemicals, etc.) and drinking water has become very important because these media are vulnerable 2 to $\mathrm{As}^{3+}$ contamination. ${ }^{4}$ Among many developed methods for toxic metal ions detection, 5,6 3 electrochemical (EC) techniques especially, low-cost stripping voltammetry has gained 4 considerable interest in terms of sensitivity, portability, rapid analysis time and suitable for on-site 5 detection. ${ }^{7,8}$ The performance of such methods, however, depends heavily on the materials used 6 for detection purposes.

Over the decades metal oxide nanoparticles (NPs) with their strong adsorption ability or 8 electrocatalytic activity against toxic metal ions were explored to improve the EC sensor 9 technology ${ }^{9-12}$ However, owing to the electrode fouling and inferior electrical conductivity, most 10 of the metal oxide NPs suffer from long-term stability and unfavorable electron transfer kinetics. ${ }^{13}$ 11 On the other hand, graphene and its associates (graphene oxide/reduced graphene oxide) have 12 gained significant attention in the field of electrochemistry, due to their tunable electrical 13 conductivity, high electron mobility, and large surface area. ${ }^{14-16}$ The combination of graphene with 14 metal oxide NPs can, therefore, overcome the drawbacks present in the metal oxides and can 15 provide a modern EC platform for the detection of toxic metal ions. Up to now $\mathrm{Fe}_{3} \mathrm{O}_{4}, \mathrm{Fe}_{2} \mathrm{O}_{3}$, $16 \mathrm{MnO}_{2}, \mathrm{PbO}$ based graphene nanocomposites(NCs) have been utilized with great success for $\mathrm{As}^{3+}$ 17 detection. ${ }^{17-19}$ Among these metal oxides, environmental friendly $\mathrm{Fe}_{3} \mathrm{O}_{4} / \mathrm{Fe}_{2} \mathrm{O}_{3}$ NPs or nanosheets 18 have shown a higher affinity towards $\mathrm{As}^{3+}{ }^{7}$ But sophisticated synthesis protocols of such NCs 19 lead to an increase in the material production cost. Therefore, a facile approach to prepare low20 cost NCs, consist of graphene and many metal oxide phases could be of great significance in the 21 field of EC sensor.

Red mud (RM) is an aluminum industry waste, composed of fine particles containing $\mathrm{Fe}_{2} \mathrm{O}_{3}$ 23 (30-60\%) constitutes; in addition, other metal oxides like $\mathrm{Al}_{2} \mathrm{O}_{3}, \mathrm{SiO}_{2}, \mathrm{TiO}_{2}$ are also present. ${ }^{20}$ It 24 possesses large surface areas and available at large scale at practically no cost. However, it is 25 highly alkaline in nature and now is a threat to the ecosystem due to the high volume of RM 26 production, processing, and maintenance. RM is well known to have high adsorption capacity 27 towards toxic metal ions and it has been used for the removal of these environmental carcinogens 28 for decades. ${ }^{21}$ Interestingly, the applicability of red mud as an EC sensor towards toxic metal ion 29 detection has not been explored yet. 
Thus motivated by the need for a cost-effective, robust, environmental friendly sensor for $\mathrm{As}^{3+}$ detection in water and to utilize the excellent adsorption capabilities of RM, herein we report the applicability of RM-reduced graphene oxide (RM-rGO) $\mathrm{NCs}$ for $\mathrm{As}^{3+}$ detection using square wave anodic stripping voltammetry (SWASV) technique. The evaluation of EC studies of the new NCs exhibit excellent limit of detection (LOD), sensitivity and anti-interference activity towards $\mathrm{As}^{3+}$ ions.

\title{
EXPERIMENTAL SECTION
}

\author{
RM was collected from National Aluminum Company Limited (NALCO), India. All
} chemicals including, graphite flakes ( $>99 \%$ Alfa Aesar), sulphuric acid (98\%, Fisher Scientific) and hydrochloric acid (37\%, Fisher Scientific), potassium permanganate ( $>99 \%$, Sigma Aldrich), sodium hydroxide (98\%, Fisher Scientific), L-ascorbic acid (99\%, Sigma Aldrich), potassium ferrocyanide $\left(\mathrm{K}_{4}\left[\mathrm{Fe}(\mathrm{CN})_{6}\right]\right)$, potassium ferricyanide $\left(\mathrm{K}_{3}\left[\mathrm{Fe}(\mathrm{CN})_{6}\right]\right)$, potassium chloride $(\mathrm{KCl})$ (Fisher Scientific) were used as received without any further purification. A stock solution ( $1 \mathrm{~g} / \mathrm{L})$ of $\mathrm{As}^{3+}$ was prepared by dissolving the required quantity of $\mathrm{As}_{2} \mathrm{O}_{3}$ in $\mathrm{NaOH}$ solution, and subsequently, the $\mathrm{pH}$ of the solution was adjusted to 3 with concentrated $\mathrm{HCl}$. For interference study, the standard solutions of $\mathrm{Cd}^{2+}, \mathrm{Cr}^{2+}, \mathrm{Zn}^{2+}, \mathrm{Cu}^{2+}, \mathrm{Pb}^{2+}, \mathrm{Hg}^{2+}$ ions (1000 ppm each) were purchased from Sigma Aldrich and were diluted to make a solution of the desired concentration.

First, rGO was synthesized using sonication assisted oxidation of graphite in an acidic environment as reported by Sina Abdolhosseinzadeh et al. ${ }^{22}$ In order to prepare the nano RM-rGO composite, mechanical milling process using a planetary ball mill (Retsch, PM200) was employed. The powders (mass ratio of RM to rGO is 10:1) were placed in a chrome steel bowl (volume 60 $\mathrm{mL}$ ) filled with steel balls of diameter $5 \mathrm{~mm}$ with balls-to-powder mass ratio was 10:1. The ball milling was carried out at 150 revolutions per minute (rpm) and was continued up to $12 \mathrm{hr}$. with intermediate intervals of $2 \mathrm{hr}$. The prepared samples are designated as $\mathrm{RM}-\mathrm{rGO}_{\mathrm{Z}} \mathrm{NCs}$ where $\mathrm{Z}$ is the milling hour.

X-ray diffraction (XRD) experiments were performed using Bruker, D8-discover with $\mathrm{Cu}-\mathrm{K}_{\alpha}$ energy $(\lambda=0.154 \mathrm{~nm})$. The Raman spectra were recorded using a Renishaw Raman spectrometer (inVia) using a $532 \mathrm{~nm}$ Laser source, using a nominal power of $25 \mathrm{~mW}$ for $60 \mathrm{~s}, 50 \times$ magnification. Fourier transform infrared spectroscopy was performed using Thermo Scientific Nicolet ${ }^{\text {TMiS }}{ }^{\text {TM}} 5$ FTIR with a diamond ATR accessory. Scanning electron microscopy was carried out using a Hitachi SU5000, with an acceleration voltage of $10 \mathrm{kV}$ and working distance $\square 6 \mathrm{~mm}$. All EC 
measurements were done using the Autolab potentiostat/galvanostat 302N instrument (Metrohm

2 Autolab B.V. Utrecht, Netherlands) controlled by NOVA software.

3

\section{RESULTS AND DISCUSSION}




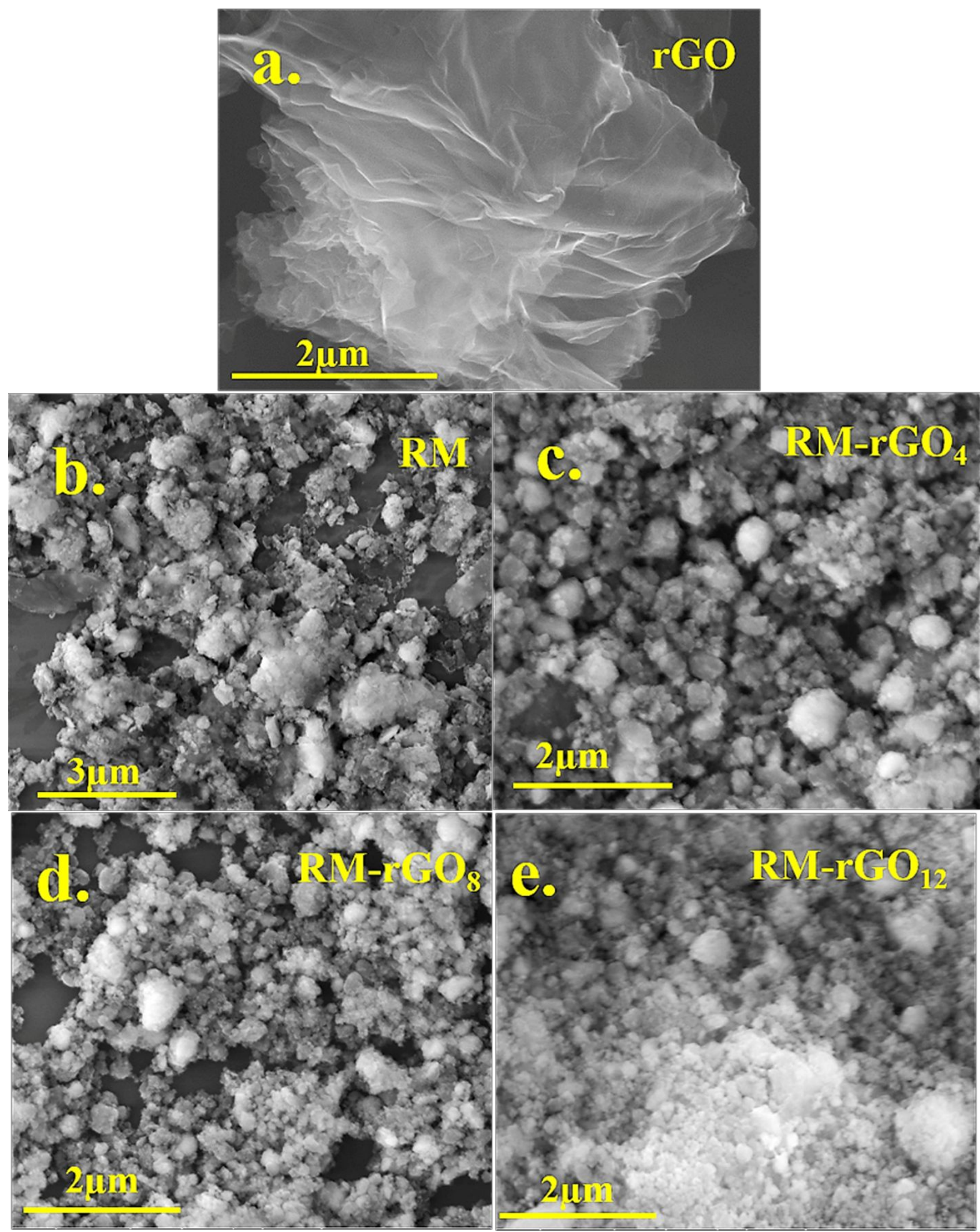

2 Figure 1 SEM images of (a) rGO (b) RM (c) RM-rGO 4 (d) RM-rGO 8 and (e) RM-rGO $\mathrm{R}_{12}$. 
In order to investigate the charge transfer kinetics of the prepared NCs, cyclic voltammetry

$2(\mathrm{CV})$ measurements were performed using an EC redox couple $\left(\left[\mathrm{Fe}(\mathrm{CN})_{6}\right]^{3-/ 4-}\right.$ in $\left.0.1 \mathrm{M} \mathrm{KCl}\right)$, which

3 is displayed in Figure 2a. It is well known that both the degree of reversibility and the charge

4 transfer kinetics, can be improved by eliminating oxygen-containing groups or by increasing the

5 fraction of $\mathrm{sp}^{2}$ bonded carbons in carbon-based NCs. ${ }^{24}$ In our case, the smallest $\Delta \mathrm{E}_{\mathrm{p}} \square 0.15 \mathrm{~V}$

6 (anodic and cathodic peak potential separation) and the highest peak current is observed for

$7 \mathrm{RM} / \mathrm{rGO}_{8} \mathrm{NCs}$. Further, the ratio of anodic to cathodic peak current $\left(i_{\mathrm{pa}} / i_{\mathrm{pc}}\right)$ is calculated as 1.08

8 for $\mathrm{RM} / \mathrm{rGO}_{8}$, indicating a reversible electron transfer process of the $\mathrm{Fe}^{2+} / \mathrm{Fe}^{3+}$ species. The $\mathrm{CV}$

9 output of $\mathrm{RM} / \mathrm{rGO}_{12}$ is also comparable to that of $\mathrm{RM} / \mathrm{rGO}_{8}$. From the scan rate dependency $\mathrm{CV}$

10 curves of $\mathrm{RM} / \mathrm{rGO}_{8}$ (inset of Figure $2 \mathrm{a}$ ), it can be visualized that redox peak currents $\left(i_{\mathrm{pa}}\right.$ and $\left.i_{\mathrm{pc}}\right)$

11 are increases linearly with the square root of scan rate (insets of Figure 2a), implies diffusion-

12 controlled redox kinetics of the $\mathrm{Fe}^{2+} / \mathrm{Fe}^{3+}$ species. The $\mathrm{CV}$ performance of $\mathrm{RM}-\mathrm{rGO}_{2}, \mathrm{RM}_{-} \mathrm{rGO}_{6}$,

13 and $\mathrm{RM}-\mathrm{rGO}_{10}$ is also represented in Figure $\mathrm{S} 1$. The $\mathrm{CV}$ output of $\mathrm{RM}-\mathrm{rGO}_{6}$ and $\mathrm{RM}-\mathrm{rGO}_{10}$ are

14 approximately equal to that of $\mathrm{RM}-\mathrm{rGO}_{4}$ and $\mathrm{RM}-\mathrm{rGO}_{12}$ respectively whereas, the lowest peak

15 current is observed for $\mathrm{RM}-\mathrm{rGO}_{2}$.

Figure $2 \mathrm{~b}$ represents the SWASV analytical characteristics of GCE, RM and all RM-rGO

17 NCs where electrodeposition is carried out for $200 \mathrm{~s}$ at $-0.4 \mathrm{~V}$. Nearly no oxidation peak is 18 observed for the bare GCE electrode. For RM particles there is only a weak peak can be seen. This 19 is probably due to the inferior electrical conductivity of the RM. However, the RM-rGO NCs 20 provide a much greater and sharper peak current response towards the $\mathrm{As}^{3+}$ ions. Figure $2 \mathrm{~b}$ clearly 21 shows that $\mathrm{RM}^{-\mathrm{rGO}_{8}}$ outperforms the other electrodes in terms of stripping peak current response 22 corresponds to the oxidation of $\mathrm{As}^{0}$. $\mathrm{RM}-\mathrm{rGO}_{8}$ is, therefore, best suited for $\mathrm{As}^{3+}$ detection which 23 results in better sensitivity.

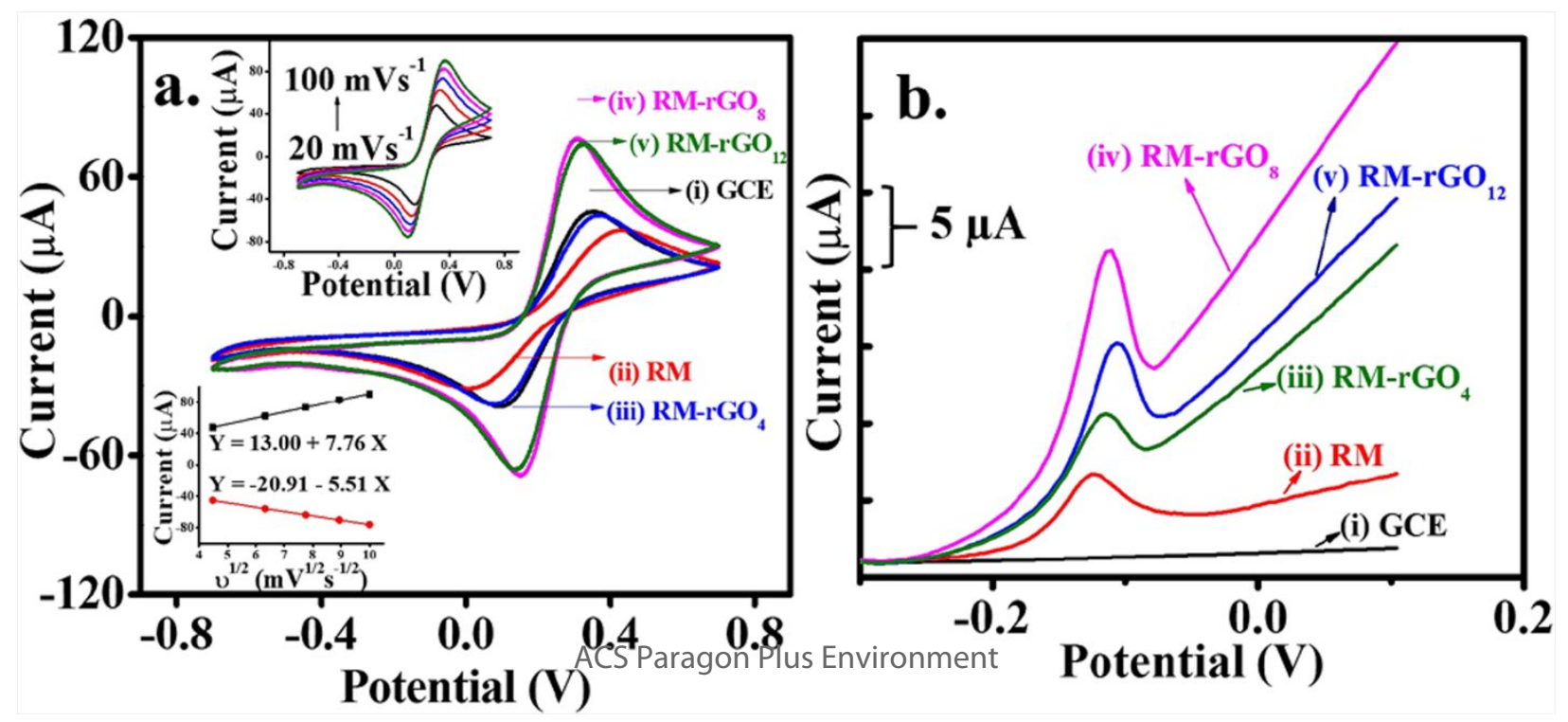


Figure 2 (a) CV response of (i) GCE (ii) RM (iii) $\mathrm{RM}^{-\mathrm{rGO}_{4}}$ (iv) $\mathrm{RM}-\mathrm{rGO}_{8}$ and (v) $\mathrm{RM}-\mathrm{rGO}_{12}$ with insets showing the $\mathrm{CV}$ response of $\mathrm{RM}-\mathrm{rGO}_{8}$ with scan rate $20,40,60,80$ and $100 \mathrm{mVs}^{-1}$ and the variation of the anodic and cathodic peak current of $\mathrm{RM}^{-\mathrm{rGO}_{8}}$ as a function of scan rate. (b) SWASV response of (i) GCE (ii) RM (iii) RM-rGO (iv) RM$\mathrm{rGO}_{8}$ and (v) $\mathrm{RM}^{-\mathrm{rGO}_{12}}$ for the detection of $10 \mathrm{ppb} \mathrm{As}{ }^{3+}$ ions. The SWASV experimental parameters are as follows: deposition time $200 \mathrm{~s}$, deposition potential $-0.4 \mathrm{~V}$, amplitude $25 \mathrm{mV}$, step potential $4 \mathrm{mV}$ and frequency $25 \mathrm{~Hz}$. optimized (Figure S2) to achieve the maximum sensing efficiency using RM-rGO 8 NCs. Finally,

Next, experimental parameters (deposition potential and time) of SWASV experiment are the detection of $\mathrm{As}^{3+}$ is accomplished under the optimized experimental conditions (deposition potential of $-0.4 \mathrm{~V}$ and deposition time $200 \mathrm{~s}$ ). Figure 3 a represents the SWASV response for $\mathrm{As}^{3+}$ at various concentrations. The electrooxidation current was linear within the concentration range of 0.5 to $3.7 \mathrm{ppb}$ (inset of Figure $3 \mathrm{a}$ ) and the fitted linear relationship between the stripping peak current (corresponds to the oxidation of $\mathrm{As}^{0}-\mathrm{As}^{3+}$ ) and concentration of $\mathrm{As}^{3+}$ is described by the following equation $\mathrm{i} / \mu \mathrm{A}=-0.59+2.49 \mathrm{c} / \mathrm{ppb}$. The limit of detection (LOD) and sensitivity value was found to be $0.07 \mathrm{ppb}$ and $2.49 \mu \mathrm{Appb}^{-1}$ respectively. Where LOD is defined as the, lowest quantity of analyte that provides a signal which is significantly different from the blank value with a stated confidence level of $90 \%$ and the LOD value is calculated according to the literature reported. ${ }^{25}$ The obtained LOD value is well below the WHO toxicity mark (10 ppb). ${ }^{3} \mathrm{~A}$ comparative study of the performance of the $\mathrm{RM}-\mathrm{rGO}_{8} / \mathrm{GCE}$ electrode with other sensing platforms developed for EC detection of $\mathrm{As}^{3+}$ is summarized in Table 1.

To validate the selectivity of the $\mathrm{RM}-\mathrm{rGO}_{8} / \mathrm{GCE}$ electrode with the co-occurrence of $\mathrm{As}^{3+}$ and $\mathrm{Cu}^{2+}$ ions, SWASV measurements were carried out again in a mixture of both the ions where the concentration of $\mathrm{Cu}^{2+}$ was kept higher than $8 \mathrm{ppb}$. Figure $3 \mathrm{~b}$ represents the SWASV plots of simultaneous detection of $\mathrm{As}^{3+}$ and $\mathrm{Cu}^{2+}$. An isolated anodic peak corresponding to the oxidation of $\mathrm{Cu}^{0}-\mathrm{Cu}^{2+}$ is observed at around $0.3 \mathrm{~V}$ which is far away $(\sim 400 \mathrm{mV})$ from the anodic peak potential of $\mathrm{As}^{0}$. Here the concentration of $\mathrm{As}^{3+}$ and $\mathrm{Cu}^{2+}$ is increased simultaneously and the obtained sensitivity of $\mathrm{As}^{3+}$ is marginally improved compared to that observed in the absence of $\mathrm{Cu}^{2+}$. The enhanced sensitivity of $\mathrm{As}^{3+}$ can be explained on the basis of interference between $\mathrm{As}^{3+}$ and $\mathrm{Cu}^{2+}$ ions. The stripping peak potentials of both the ions are far from each other $(400 \mathrm{mV})$ and the formation of an intermetallic compound is most unlikely, but small peaks in between $\mathrm{As}^{3+}$ and $\mathrm{Cu}^{2+}$ are visible which may be due to the formation of $\mathrm{As}-\mathrm{Cu}$ intermetallic compound during the simultaneous existence arsenic and copper. Such kinds of observations are well documented and 
1 have been published before. ${ }^{26}$ The influence of other metal ions on the stripping current response

2 of $\mathrm{As}^{3+}$ has been further demonstrated by doing interference experiments.

3
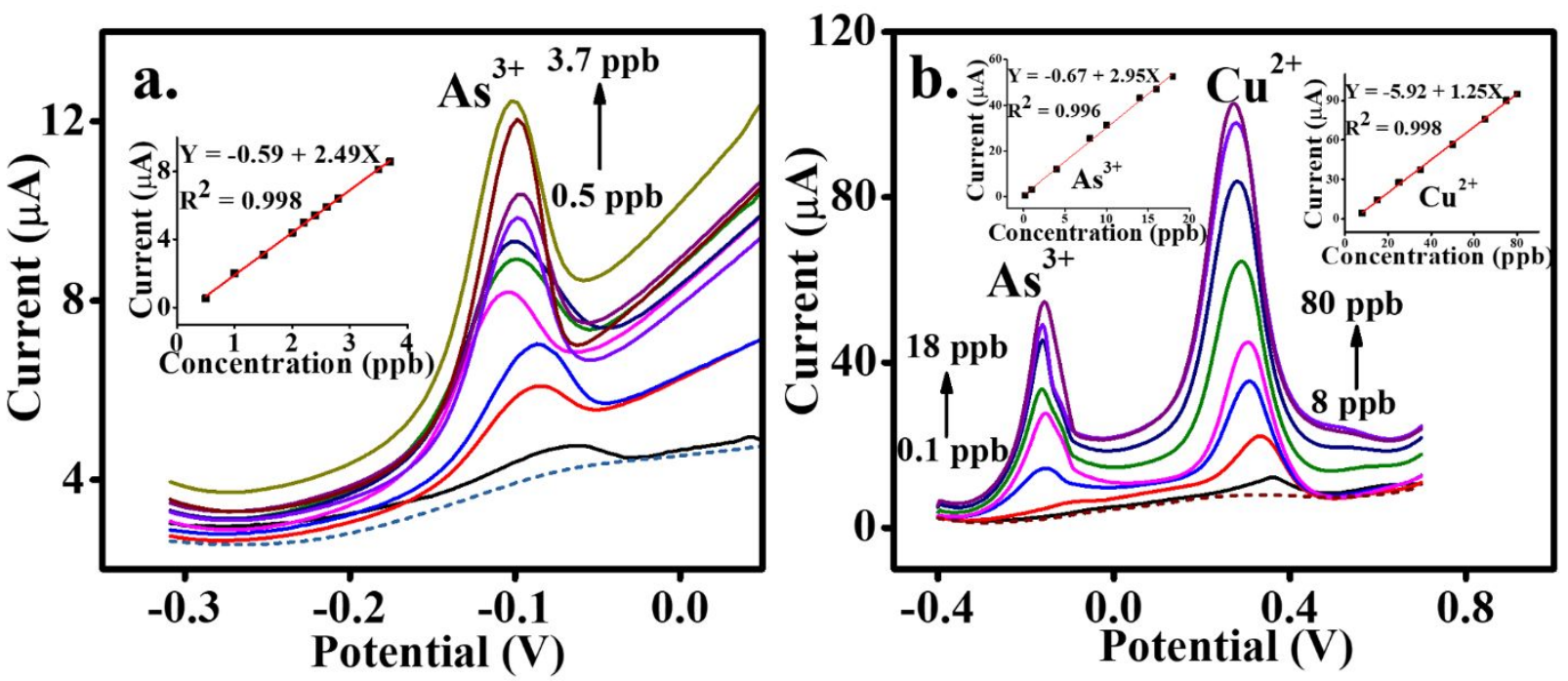

4

Figure 3 (a) SWASV response of $\mathrm{RM}-\mathrm{rGO}_{8}$ towards the detection of $\mathrm{As}^{3+}$ ions over a concentration range of 0.5 to $3.7 \mathrm{ppb}$. The inset of Figure (a) displays the linear calibration plot of the peak current as a function of $\mathrm{As}^{3+}$ ions concentration. (b) SWASV response of $\mathrm{RM}-\mathrm{rGO}_{8}$ for the simultaneous detection of $\mathrm{As}^{3+}(0.1$ to $18 \mathrm{ppb})$ and $\mathrm{Cu}^{2+}(8$ to $80 \mathrm{ppb}$ ) with insets show the linear calibration plots corresponding to the $\mathrm{As}^{3+}$ and $\mathrm{Cu}^{2+}$ ions concentration.

Table 1. Comparison of our proposed electrode material with other sensing platforms.

\begin{tabular}{cccc}
\hline Electrode material & $\begin{array}{c}\text { Sensitivity } \\
(\boldsymbol{\mu A} / \mathbf{p p b})\end{array}$ & $\begin{array}{c}\text { LOD } \\
(\mathbf{p p b})\end{array}$ & Ref. \\
\hline CoOx/GCE & 0.00148 & 0.825 & 27 \\
$\mathrm{Fe}_{3} \mathrm{O}_{4}$ room temperature ionic liquid composite & 4.91 & 0.0008 & 10 \\
$\mathrm{Ru}$ nanoparticle/GCE & 0.00238 & 0.1 & 28 \\
Gold nanoparticles & 2.69 & 0.06 & 29 \\
$\mathrm{Au}-\mathrm{Pd}$ bimetallic nanoparticle & 3.9 & 0.024 & 30 \\
$\mathrm{FePt}$ bimetallic nanoparticle & 0.42 & 0.8 & 31 \\
$\mathrm{MnOx} / \mathrm{Au}$ nanoparticle composite & 0.193 & 0.057 & 9 \\
$\mathrm{MnFe}_{2} \mathrm{O}_{4}$ nanocrystal/gold electrode & 0.295 & 1.95 & 32 \\
$\mathrm{rGO} / \mathrm{MnO}_{2}$ nanohybrid & 0.175 & 0.05 & 18 \\
$\mathrm{rGO} / \mathrm{Fe}_{3} \mathrm{O}_{4}$ nanocomposites & 0.281 & 0.12 & 19 \\
$\mathrm{Dumbbell} \mathrm{like} \mathrm{Au} / \mathrm{Fe} \mathrm{O}_{4}$ nanoparticles & 9.43 & 0.02 & 33 \\
$\mathrm{Graphene} / \mathrm{PbO}$ composite & - & 0.74 & 17
\end{tabular}

RM-rGO composite

2.49

0.07

Present work

Analysis of $\mathrm{As}^{3+}$ in the presence of other interfering agent is still difficult, as coexisting substances are co-deposited and stripped with $\mathrm{As}^{3+}$. Therefore selective detection of $\mathrm{As}^{3+}$ in the presence of other metal ions is also important. In order to investigate the anti-interference ability 
of the $\mathrm{RM}-\mathrm{rGO}_{8} / \mathrm{GCE}$ electrode, SWASV measurements are recorded in $10 \mathrm{ppb} \mathrm{As}^{3+}$ solution in

2 the presence of a 10 fold higher concentration of other metal ions namely $\mathrm{Cd}^{2+}, \mathrm{Cr}^{2+}, \mathrm{Zn}^{2+}, \mathrm{Cu}^{2+}$,

$3 \mathrm{~Pb}^{2+}$, and $\mathrm{Hg}^{2+}$. Figure 4 illustrates the anodic stripping current of the $\mathrm{As}^{3+}$ in the absence and

4 presence of the above mentioned interfering metal ions. No significant interference is observed of

5 these ions on the $\mathrm{As}^{3+}$ stripping current response. The optimized deposition potential $(-0.4 \mathrm{~V})$

6 eliminates the possible interference from common metal cations. ${ }^{19}$ In addition, rapid mass

7 transportation in the electrode surface with a small diffusion layer and high current density could

8 also be responsible for such good anti-interference activity. This interference study laid the

9 foundation for reliable and selective $\mathrm{As}^{3+}$ detection in water.

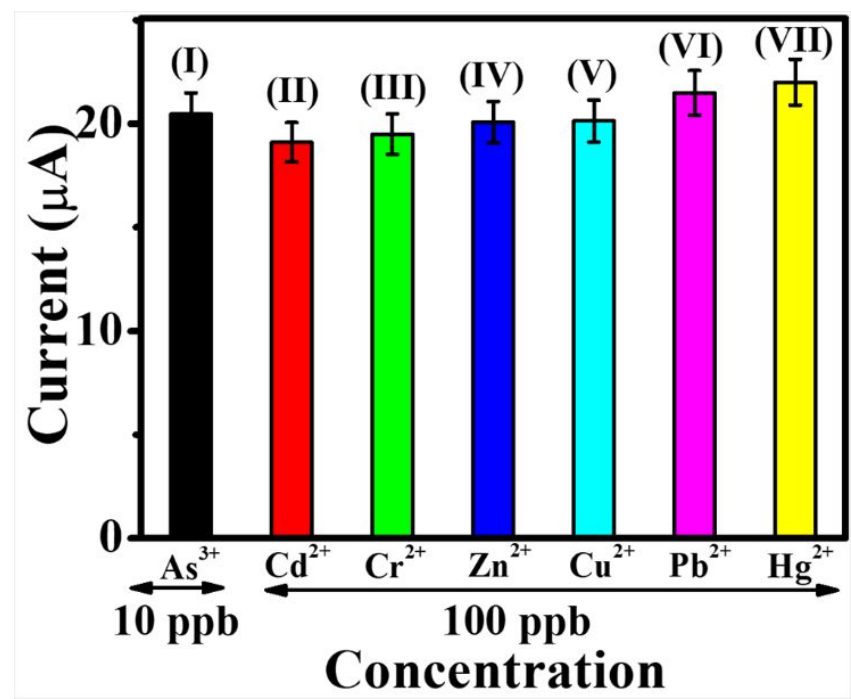

12 Figure 4 Effect of interfering ions $\mathrm{Cd}^{2+}, \mathrm{Cr}^{2+}, \mathrm{Zn}^{2+}, \mathrm{Cu}^{2+}, \mathrm{Pb}^{2+}$, and $\mathrm{Hg}^{2+}$ on the stripping current response of $10 \mathrm{ppb}$ $13 \mathrm{As}^{3+}$.

To demonstrate the compatibility of $\mathrm{RM}^{-\mathrm{rGO}_{8}} \mathrm{NCs}$ with the Au electrode, similar SWASV 16 (diameter $=2 \mathrm{~mm}$ ) equal to GCE. Figure S3 (supporting information) displays the typical SWASV 17 curves for the $\mathrm{As}^{3+}$ (0.1 to $\left.2.1 \mathrm{ppb}\right)$ detection with inset represents the linear calibration plot. 18 Interestingly, the anodic peak corresponds to the oxidation of $\mathrm{As}^{0}-\mathrm{As}^{3+}$ occurs around (0.2 V) 19 which is more positive as compared to the $\mathrm{RM}-\mathrm{rGO}_{8}$ modified GCE electrode. The obtained 20 sensitivity and LOD are found to be $4.35 \mu \mathrm{A} \mathrm{ppb}^{-1}$ and $0.08 \mathrm{ppb}$ respectively. Though the RM$21 \mathrm{rGO}_{8} / \mathrm{Au}$ electrode affords better sensitivity compared to $\mathrm{RM}-\mathrm{rGO}_{8} / \mathrm{GCE}$, it is still prone to 
1 interference from other metal ions, in particular from $\mathrm{Cu}^{2+}$ ions, which has a redox potential 2 (around $0.338 \mathrm{~V}$ ) very near to the oxidation potential of $\mathrm{As}^{0}$.

Metal oxide nanomaterials are prone to instability under acidic media, hence taking the 4 practical applications into account the reproducibility and stability test of the $\mathrm{RM}-\mathrm{rGO}_{8} \mathrm{NCs}$ is 5 carried out in acidic conditions. A series of 6-time repetitive measurements of SWASV response 6 for $2 \mathrm{ppb}$ of $\mathrm{As}^{3+}$ is recorded and the results are displayed in Figure S4. The stripping current 7 response of the $\mathrm{RM}-\mathrm{rGO}_{8}$ electrode is highly reproducible with a relative standard deviation of $83.57 \%$. The nanocomposite's stability is also investigated and the SWASV current response corresponds to the arsenic oxidation remaining $\square 90 \%$ of its initial response after 15 days. Therefore, the good electrode stability and reproducibility for repetitive measurements of $\mathrm{As}^{3+}$ ions indicate that the nanocomposite possesses great potential for monitoring $\mathrm{As}^{3+}$ ions in real samples. In order to examine the practical application of the present $\mathrm{NC}\left(\mathrm{RM}^{-} \mathrm{rGO}_{8}\right)$, the SWASV experiment has been performed on the real water sample. The sample was collected from the groundwater near Asansol city, West Bengal, India. Prior to the SWASV experiment, the sample was treated with a filter to remove any insoluble contaminants. The water sample was then diluted with concentrated $\mathrm{HCl}$ to adjust its $\mathrm{pH}$ value to 3 and no further sample treatment was done. The 17 standard addition of $\mathrm{As}^{3+}$ is performed to calculate the concentration of $\mathrm{As}^{3+}$ in the real sample. The SWASV response and the corresponding calibration plots are shown in Figure S5 and the $\mathrm{As}^{3+}$ concentration in the real sample is calculated as $2.24 \mathrm{ppb}$. To determine the validity of the electrochemical method we discussed, recovery experiments are also performed with the real sample in which a known amount of $\mathrm{As}^{3+}$ is added. The obtained recovery is varied between $90 \%$ to $110 \%$ which indicates the $\mathrm{RM}-\mathrm{rGO}_{8}$ nanocomposite has a great practical application.

There are many factors that can influence the EC behavior of RM-rGO NCs, such as surface morphology, the active surface area for EC reaction, the fraction of $\mathrm{sp}^{2}$ bonded carbons come in contact with the electrolyte, etc. The optimization of milling time is another aspect that requires further analysis in terms of identifying the morphological, chemical and physical changes. In addition, the shift in the peak current (anodic $/ i_{p a}$ and cathodic $/ i_{\mathrm{pc}}$ ) response and peak potential difference $\left(\Delta \mathrm{E}_{\mathrm{p}}\right)$ in the $\mathrm{CV} i$-E curve may be correlated to the surface oxygen functionalities and the exposed edge planes of $\mathrm{sp}^{2}$ bonded carbons. In order to identify the factors responsible for the strong EC sensing results, XRD, Raman and FTIR spectroscopic tools are employed. 
To determine the different phases present in the as obtained RM and synthesized RM-rGO

2 NCs, XRD measurements were carried out and are represented in Figure 5a. In case of rGO, a broad diffraction peak around $2 \theta \sim 25^{\circ}$ and a small peak at $2 \theta \sim 43^{\circ}$ can be seen (Figure 5a(i)) which signifies the formation of rGO with less oxygen functionalities. ${ }^{34}$ Whereas, in RM and all RM-rGO NCs, a mixture of many metal oxide phases such as hematite, goethite, calcite, and silica can be observed. However, hematite $\left(\theta \sim 12.06^{\circ}, 16.57^{\circ}, 17.80^{\circ}\right)$ is the main dominant phase in $\mathrm{RM}$ which is expected due to the red color of the RM and it constitutes around $55 \%$ of the RM. ${ }^{35}$

The reduction in particle size via ball milling can also be correlated with the XRD peak broadening with milling hour. Notably, in all RM-rGO NCs, the broad diffraction peak of rGO can be observed, indicating that rGO sheets are attached to the RM particles.

Raman measurements were also carried out to examine the phase purity and different vibrational modes present in the NCs. A series of band related to the different modes of vibration of metal oxides, e.g; $\mathrm{Eg}\left(\sim 291\right.$ and $\left.404 \mathrm{~cm}^{-1}\right)$ and $\mathrm{A}_{1 \mathrm{~g}}\left(\sim 223\right.$ and $\left.502 \mathrm{~cm}^{-1}\right)$ mode of hematite $\left(\mathrm{Fe}_{2} \mathrm{O}_{3}\right)$ phase; $\mathrm{E}_{\mathrm{g}}{ }^{5}\left(\sim 146 \mathrm{~cm}^{-1}\right)$ and $\mathrm{A}_{\mathrm{G}}{ }^{1}\left(\sim 662 \mathrm{~cm}^{-1}\right)$ mode of ilmenite $\left(\mathrm{FeTiO}_{3}\right)$ phase; $\mathrm{Eg}(\sim 152$ $\left.\mathrm{cm}^{-1}\right)$ mode corresponds to the calcite $\left(\mathrm{CaCO}_{3}\right)$ phase can be seen in the Raman spectrum of RM (Figure $5 b(\mathrm{i})$ ). ${ }^{35}$ Raman spectrum of rGO and RM-rGO NCs display a typical characteristic peak of $\mathrm{D}$ and $\mathrm{G}$ band around 1345 and $1595 \mathrm{~cm}^{-1}$, where $\mathrm{D}$ peak corresponds to the rGO sheet defects and $\mathrm{G}$ peak is related to $\mathrm{E}_{2 \mathrm{~g}}$ phonon modes of the $\mathrm{sp}^{2}$ bonded carbon. The relative intensity ratio of these two bands $\left(\mathrm{I}_{\mathrm{D}} / \mathrm{I}_{\mathrm{G}}\right)$ is a simple way to quantify the degree of disorder present in the graphene sheet. In case of $\mathrm{rGO}$, the ratio of the $\mathrm{I}_{\mathrm{D}} / \mathrm{I}_{\mathrm{G}}$ is 1.00 and the value is increased to 1.13 for the RM$\mathrm{rGO}_{8}$ sample, which implies that the physical force during the milling process introduces defects and disorder to the graphene cluster. Further milling up to $12 \mathrm{hr}$. did not change much the value of $\mathrm{I}_{\mathrm{D}} / \mathrm{I}_{\mathrm{G}}$ that indicates, $\mathrm{rGO}$ sheets are attached well to the RM particles which help graphene sheets to damage further.

Furthermore, FTIR spectroscopy examines the deoxidation of rGO and the presence of chemical bonds or attached functional groups in RM and RM-rGO NCs. In the case of rGO (Figure $5 \mathrm{c}(\mathrm{i}))$, the peak at $1560 \mathrm{~cm}^{-1}$ and a weak signal around $1685 \mathrm{~cm}^{-1}$ is referred to as the $\mathrm{C}=\mathrm{C}$ and $\mathrm{C}=\mathrm{O}$ stretching vibration respectively. However, other oxygen-containing functionalities such as epoxy or alkoxy groups (C-O) are completely absent in rGO which are the common features of graphene oxides FTIR spectra. ${ }^{36}$ This observation confirms that most of the oxygen-containing functional groups are removed from the graphene sheet during the reduction process. On the other 
1 hand, RM shows a strong absorption band around $595 \mathrm{~cm}^{-1}$ and a weak peak near $1645 \mathrm{~cm}^{-1}$ due 2 to the stretching vibration of $\mathrm{Fe}-\mathrm{O}$ bonds of the hematite phase. ${ }^{37}$ In addition, the presence of 3 goethite $\left(\sim 803 \mathrm{~cm}^{-1}\right)$, characteristics bands correspond to the Si-O vibrations $\left(\sim 990 \mathrm{~cm}^{-1}\right)$, presence 4 of $\mathrm{CO}_{3}^{2-}\left(\sim 1420,866 \mathrm{~cm}^{-1}\right)$ groups are also detected. The positions and absorption bands of RM5 rGO NCs (Figure 5c(iii-v)) are nearly similar to that of RM. The rGO sheets are likely anchored 6 to the nano RM particles through carboxylate bonds ( $\mathrm{Fe}-\mathrm{C}-\mathrm{O})$ and the existence of which is 7 confirmed in the FTIR spectra (band around $1580 \mathrm{~cm}^{-1}$ ) of RM-rGO NCs. ${ }^{38}$ The existence of some 8 additional bands in the hydroxyl stretching region $\left(\sim 3300-3500 \mathrm{~cm}^{-1}\right)$ can also be seen in RM9 rGO NCs. These attached hydroxyl functional groups in the RM-rGO NCs are advantageous for 10 adsorbing toxic metal ions. ${ }^{13}$ 

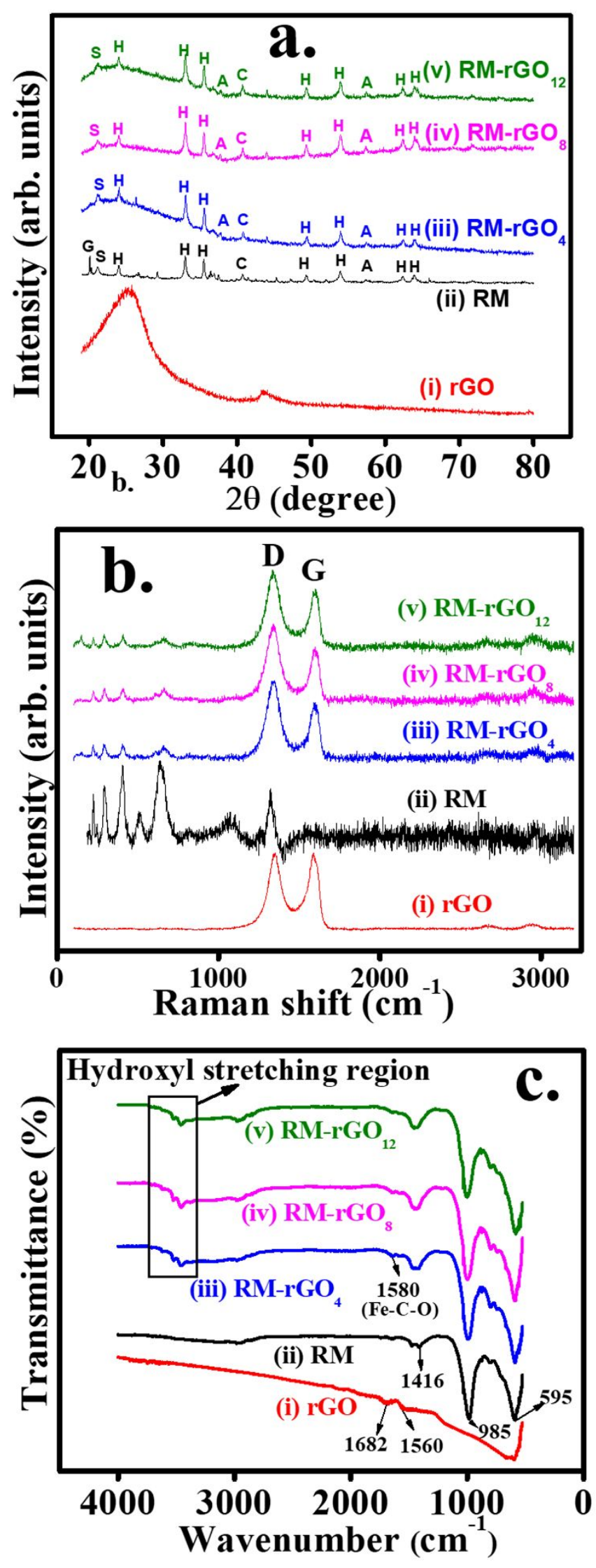
Figure 5 (a) XRD pattern (b) Raman spectra and (c) FTIR spectra of (i) rGO (ii) RM (iii) $\mathrm{RM}^{-r_{G}} \mathrm{O}_{4}$ (iv) $\mathrm{RM}^{-\mathrm{rGO}_{8}}$

2 and (v) $\mathrm{RM}^{-\mathrm{rGO}_{12}}$.

3

Thus, the key feature for the excellent EC performance is related to the high adsorption capability of the hematite phase rich RM. The formation of nano RM via mechanical milling increases the active surface area to adsorb $\mathrm{As}^{3+}$ ions while the presence of $\mathrm{sp}^{2}$ bonded carbons in

7 the rGO sheets is responsible for enhanced electron transport kinetics. The superior EC behavior 8 of $\mathrm{RM} / \mathrm{rGO}_{8}$ and $\mathrm{RM} / \mathrm{rGO}_{12}$ can be attributed to the large active surface area of these NCs where 9 RM particles are properly surrounded by the $\mathrm{rGO}$ sheets and larger fraction of $\mathrm{sp}^{2}$ carbon comes 10 in contact with electrolyte during EC measurements. In addition, the attached functional groups 11 (hydroxyl and carboxylic) to the NC surface not only serve as active sites for electrodeposition of $12 \mathrm{As}^{3+}$ ions but also act as a bridge for rapid electron transfer from solution to electrode surface. 13 Therefore, the NCs prepared at longer milling hour $(>4)$ with exposed $\mathrm{sp}^{2}$ carbon and less oxygen 14 functionalities facilitates the electron transfer kinetics. The combined effect of RM and electrically 15 conductive $\mathrm{rGO}$ allows more effective electrodeposition of $\mathrm{As}^{3+}$ ions on the NCs surface, which 16 in turn improves the EC sensing performances.

\section{CONCLUSIONS}

In a time of high demand of low-cost potential nanomaterial for environmental carcinogenic detection, this work successfully demonstrates the applicability of mechanically milled RM-rGO $\mathrm{NCs}$ as a working electrode material for sensitive and efficient electroanalysis of toxic $\mathrm{As}^{3+}$ ions. The electrode $\left(\mathrm{RM}^{-} \mathrm{rGO}_{8}\right)$ can accurately detect $\mathrm{As}^{3+}$ in the presence of other interfering metal ions namely $\mathrm{Cd}^{2+}, \mathrm{Cr}^{2+}, \mathrm{Zn}^{2+}, \mathrm{Cu}^{2+}, \mathrm{Pb}^{2+}$, and $\mathrm{Hg}^{2+}$. Mechanical ball milling offers a uniform morphology and enhanced charge transfer kinetics from the low-cost industrial waste RM. However, the optimization of ball milling time is considered to be the key factor to achieve the desirable EC sensing platform. The improvement in the EC performance of RM-rGO NCs with milling time can be attributed to the formation of functionalized RM-rGO NPs which not only provide the large no of active sites for $\mathrm{As}^{3+}$ adsorption but also accelerate the electron transport kinetics. 


\section{ASSOCIATED CONTENT}

2 Supporting Information

$3 \mathrm{CV}$ response of $\mathrm{RM}-\mathrm{rGO}_{2}, \mathrm{RM}-\mathrm{rGO}_{4}, \mathrm{RM}-\mathrm{rGO}_{6}, \mathrm{RM}-\mathrm{rGO}_{8}, \mathrm{RM}-\mathrm{rGO}_{10}$, and RM-rGO 12 with inset

4 showing the magnified curve of the region A (Figure S1). Experimental parameters optimization

5 (a) deposition potential and (b) deposition time. Other experimental conditions are as follows;

6 amplitude $25 \mathrm{mV}$, step potential $4 \mathrm{mV}$ and frequency $25 \mathrm{~Hz}$ (Figure S2). SWASV response of the

$7 \quad \mathrm{RM}^{-} \mathrm{rGO}_{8} / \mathrm{Au}$ electrode towards the detection of $\mathrm{As}^{3+}$ ions over a concentration range from 0.1 to

$82.3 \mathrm{ppb}$. The inset displays the linear calibration plot of the peak current as a function of $\mathrm{As}^{3+}$ ions

9 concentration (Figure S3). The reproducibility of 6 times repetitive SWASV measurements of 2

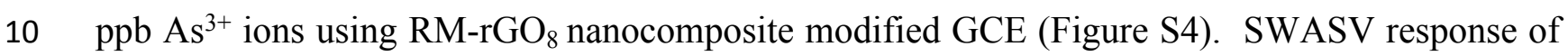
11 real water sample with successive addition of $\mathrm{As}^{3+}$ ions. The inset showing the corresponding 12 linear calibration plot of stripping peak current against $\mathrm{As}^{3+}$ concentration (Figure S5).

14 AUTHOR INFORMATION

15 Corresponding Author

16 Susanta Sinha Roy - Department of Physics, School of Natural Sciences, Shiv Nadar University, 17 NH-91, Uttar Pradesh 201314, India.

18 Orcid id- 0000-0001-5078-8877

19 Email-susanta.roy@snu.edu.in

\section{Authors}

22 Sujit Deshmukh - Department of Physics, School of Natural Sciences, Shiv Nadar University, 23 NH-91, Uttar Pradesh 201314, India.

24 Orcid id-0000-0001-7763-1693

25 Debosmita Banerjee - Department of Physics, School of Natural Sciences, Shiv Nadar University, 26 NH-91, Uttar Pradesh 201314, India.

27 Orcid id- 0000-0001-5090-257X

28 Gourav Bhattacharya - Nanotechnology and Integrated Bioengineering Centre, University of 29 Ulster, Jordanstown Campus, Newtownabbey, BT37 0QB, Northern Ireland, UK.

30 Orcid id- 0000-0001-5235-9240 


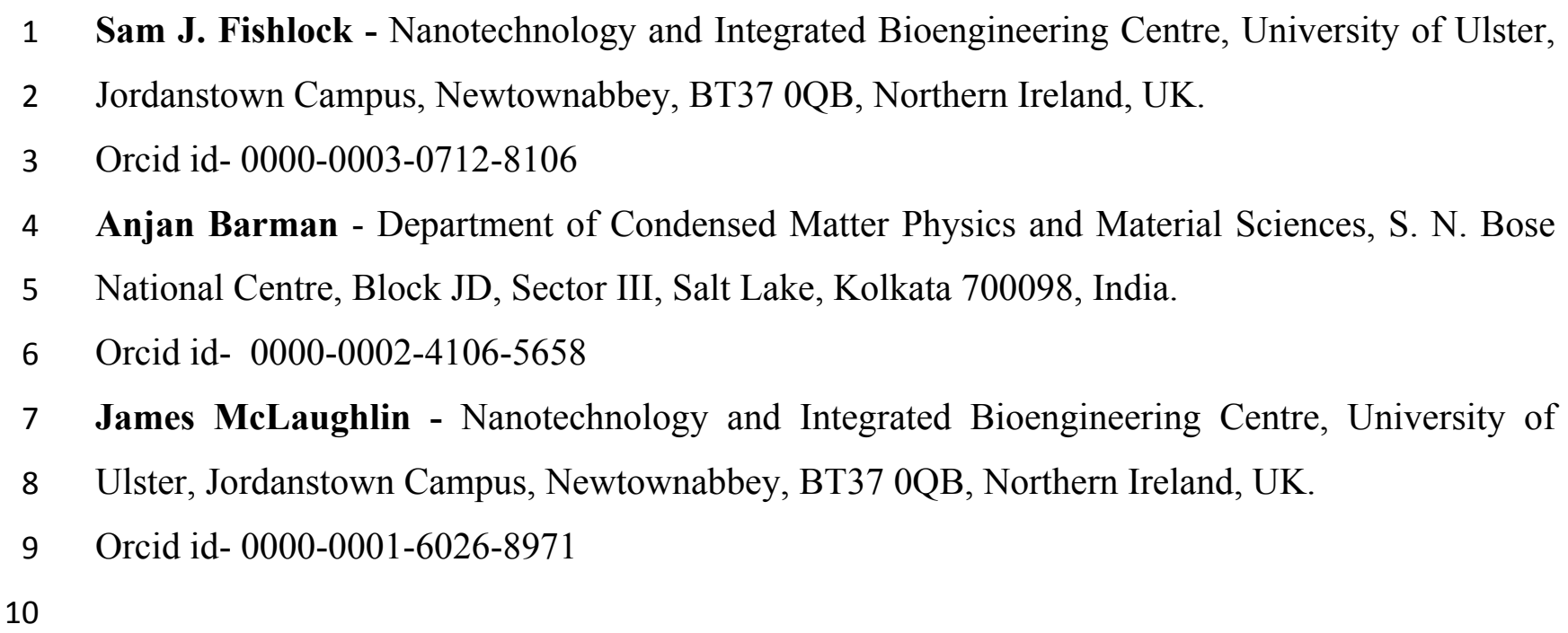

\section{CONFLICT OF INTEREST}

12 There are no conflicts to declare

14 ACKNOWLEDGMENTS

15 S. Deshmukh and D. Banerjee are indebted to Shiv Nadar University for providing PhD 16 scholarship.

\section{REFERENCES}

19 (1) Clancy, T. M.; Hayes, K. F.; Raskin, L. Arsenic Waste Management: A Critical Review of 20

(2) Smedley, P. L.; Kinniburgh, D. G. A Review of the Source, Behaviour and Distribution of Arsenic in Natural Waters. Appl. Geochemistry 2002, 17 (5), 517-568.

(3) Aragay, G.; Pons, J.; Merkoçi, A. Recent Trends in Macro-, Micro-, and Nanomaterial-

Testing and Disposal of Arsenic-Bearing Solid Wastes Generated during Arsenic Removal from Drinking Water. Environ. Sci. Technol. 2013, 47 (19), 10799-10812.

Based Tools and Strategies for Heavy-Metal Detection. Chem. Rev. 2011, 111 (5), 34333458 .

(4) Nath, P.; Arun, R. K.; Chanda, N. A Paper Based Microfluidic Device for the Detection of Arsenic Using a Gold Nanosensor. RSC Adv. 2014, 4 (103), 59558-59561.

Sengupta, M. K.; Dasgupta, P. K. Oxidation State-Differentiated Measurement of Aqueous Inorganic Arsenic by Continuous Flow Electrochemical Arsine Generation Coupled to GasPhase Chemiluminescence Detection. Anal. Chem. 2011, 83 (24), 9378-9383. 
1 (6) Mulvihill, M.; Tao, A.; Benjauthrit, K.; Arnold, J.; Yang, P. Surface-Enhanced Raman Spectroscopy for Trace Arsenic Detection in Contaminated Water. Angew. Chemie Int. Ed. 2008, 47 (34), 6456-6460.

(7) Deshmukh, S.; Kandasamy, G.; Upadhyay, R. K.; Bhattacharya, G.; Banerjee, D.; Maity, D.; Deshusses, M. A.; Roy, S. S. Terephthalic Acid Capped Iron Oxide Nanoparticles for Sensitive Electrochemical Detection of Heavy Metal Ions in Water. J. Electroanal. Chem. 2017, 788, 91-98.

(8) Reverté, L.; Prieto-Simón, B.; Campàs, M. New Advances in Electrochemical Biosensors for the Detection of Toxins: Nanomaterials, Magnetic Beads and Microfluidics Systems. A Review. Anal. Chim. Acta 2016, 908, 8-21.

(9) Wu, S.; Zhao, Q.; Zhou, L.; Zhang, Z. Stripping Analysis of Trace Arsenic Based on the MnOx/AuNPs Composite Film Modified Electrode in Alkaline Media. Electroanalysis 2014, 26 (8), 1840-1849.

(10) Gao, C.; Yu, X.-Y.; Xiong, S.-Q.; Liu, J.-H.; Huang, X.-J. Electrochemical Detection of Arsenic(III) Completely Free from Noble Metal: $\mathrm{Fe}_{3} \mathrm{O}_{4}$ Microspheres-Room Temperature Ionic Liquid Composite Showing Better Performance than Gold. Anal. Chem. 2013, 85 (5), 2673-2680.

(11) Yang, M.; Chen, X.; Jiang, T. J.; Guo, Z.; Liu, J. H.; Huang, X. J. Electrochemical Detection of Trace Arsenic(III) by Nanocomposite of Nanorod-Like $\alpha-\mathrm{MnO}_{2}$ Decorated with $\sim 5 \mathrm{Nm}$ $\mathrm{Au}$ Nanoparticles: Considering the Change of Arsenic Speciation. Anal. Chem. 2016, 88 (19), 9720-9728.

(12) Wei, Y.; Yang, R.; Zhang, Y.-X.; Wang, L.; Liu, J.-H.; Huang, X.-J. High Adsorptive $\gamma-$ $\mathrm{AlOOH}(\mathrm{Boehmite}) @ \mathrm{SiO}_{2} / \mathrm{Fe}_{3} \mathrm{O}_{4}$ Porous Magnetic Microspheres for Detection of Toxic Metal Ions in Drinking Water. Chem. Commun. 2011, 47 (39), 11062-11064.

(13) Wei, Y.; Gao, C.; Meng, F.-L.; Li, H.-H.; Wang, L.; Liu, J.-H.; Huang, X.-J. SnO $2 /$ Reduced Graphene Oxide Nanocomposite for the Simultaneous Electrochemical Detection of Cadmium(II), Lead(II), Copper(II), and Mercury(II): An Interesting Favorable Mutual Interference. J. Phys. Chem. C 2012, 116 (1), 1034-1041.

(14) Wu, S.; He, Q.; Tan, C.; Wang, Y.; Zhang, H. Graphene-Based Electrochemical Sensors. Small 2013, 9 (8), 1160-1172.

(15) Zuo, Y.; Xu, J.; Zhu, X.; Duan, X.; Lu, L.; Yu, Y. Graphene-Derived Nanomaterials as 
Recognition Elements for Electrochemical Determination of Heavy Metal Ions: A Review. Microchim. Acta 2019, 186 (3), 171.

(16) Xu, J.; Wang, Y.; Hu, S. Nanocomposites of Graphene and Graphene Oxides: Synthesis, Molecular Functionalization and Application in Electrochemical Sensors and Biosensors. A Review. Microchim. Acta 2017, 184 (1), 1-44.

(17) Ramesha, G. K.; Sampath, S. In-Situ Formation of Graphene-Lead Oxide Composite and Its Use in Trace Arsenic Detection. Sensors Actuators B Chem. 2011, 160 (1), 306-311.

(18) Devi, P.; Bansod, B.; Kaur, M.; Bagchi, S.; Nayak, M. K. Co-Electrodeposited RGO/MnO 2 Nanohybrid for Arsenite Detection in Water by Stripping Voltammetry. Sensors Actuators, $B$ Chem. 2016, 237, 652-659.

(19) Devi, P.; Sharma, C.; Kumar, P.; Kumar, M.; Bansod, B. K. S.; Nayak, M. K.; Singla, M. L. Selective Electrochemical Sensing for Arsenite Using RGO/Fe $\mathrm{O}_{4}$ Nanocomposites. $J$. Hazard. Mater. 2017, 322, 85-94.

(20) Altundoğan, H. S.; Altundoğan, S.; Tümen, F.; Bildik, M. Arsenic Adsorption from Aqueous Solutions by Activated Red Mud. Waste Manag. 2002, 22 (3), 357-363.

(21) Bhatnagar, A.; Vilar, V. J. P.; Botelho, C. M. S.; Boaventura, R. A. R. A Review of the Use of Red Mud as Adsorbent for the Removal of Toxic Pollutants from Water and Wastewater. Environ. Technol. 2011, 32 (3), 231-249.

(22) Abdolhosseinzadeh, S.; Asgharzadeh, H.; Kim, H. S. Fast and Fully-Scalable Synthesis of Reduced Graphene Oxide. Sci. Rep. 2015, 5, 10160.

(23) Bastwros, M.; Kim, G.-Y.; Zhu, C.; Zhang, K.; Wang, S.; Tang, X.; Wang, X. Effect of Ball Milling on Graphene Reinforced A16061 Composite Fabricated by Semi-Solid Sintering. Compos. Part B Eng. 2014, 60, 111-118.

(24) Granger, M. C.; Witek, M.; Xu, J.; Wang, J.; Hupert, M.; Hanks, A.; Koppang, M. D.; Butler, J. E.; Lucazeau, G.; Mermoux, M.; Strojek, J.W.; Swain, M. G. Standard Electrochemical Behavior of High-Quality, Boron-Doped Polycrystalline Diamond ThinFilm Electrodes. Anal. Chem. 2000, 72 (16), 3793-3804.

(25) Benedito da Silva, O.; Machado, S. A. S. Evaluation of the Detection and Quantification Limits in Electroanalysis Using Two Popular Methods: Application in the Case Study of Paraquat Determination. Anal. Methods 2012, 4 (8), 2348-2354.

(26) Gumpu, M. B.; Veerapandian, M.; Krishnan, U. M.; Rayappan, J. B. B. Simultaneous 
Electrochemical Detection of Cd(II), $\mathrm{Pb}(\mathrm{II}), \mathrm{As}(\mathrm{III})$ and $\mathrm{Hg}(\mathrm{II})$ Ions Using Ruthenium(II)Textured Graphene Oxide Nanocomposite. Talanta 2017, 162, 574-582.

(27) Salimi, A.; Mamkhezri, H.; Hallaj, R.; Soltanian, S. Electrochemical Detection of Trace Amount of Arsenic(III) at Glassy Carbon Electrode Modified with Cobalt Oxide Nanoparticles. Sensors Actuators B Chem. 2008, 129 (1), 246-254.

(28) Gupta, R.; Gamare, J. S.; Pandey, A. K.; Tyagi, D.; Kamat, J. V. Highly Sensitive Detection of Arsenite Based on Its Affinity toward Ruthenium Nanoparticles Decorated on Glassy Carbon Electrode. Anal. Chem. 2016, 88 (4), 2459-2465.

(29) Gu, T.; Bu, L.; Huang, Z.; Liu, Y.; Tang, Z.; Liu, Y.; Huang, S.; Xie, Q.; Yao, S.; Tu, X.; Luo, X.; Luo, S. Dual-Signal Anodic Stripping Voltammetric Determination of Trace Arsenic(III) at a Glassy Carbon Electrode Modified with Internal-Electrolysis Deposited Gold Nanoparticles. Electrochem. commun. 2013, 33, 43-46.

(30) Zhang, Q.-X.; Yin, L.-B. Electrochemical Performance of Heterostructured Au-Pd Bimetallic Nanoparticles toward As(III) Aqueous Media. Electrochem. commun. 2012, 22, $57-60$.

(31) Moghimi, N.; Mohapatra, M.; Leung, K. T. Bimetallic Nanoparticles for Arsenic Detection. Anal. Chem. 2015, 87 (11), 5546-5552.

(32) Zhou, S. F.; Han, X. J.; Fan, H. L.; Zhang, Q. X.; Liu, Y. Q. Electrochemical Detection of As(III) through Mesoporous MnFe2O4 Nanocrystal Clusters by Square Wave Stripping Voltammetry. Electrochim. Acta 2015, 174, 1160-1166.

(33) Li, S. S.; Zhou, W. Y.; Jiang, M.; Guo, Z.; Liu, J. H.; Zhang, L.; Huang, X. J. Surface $\mathrm{Fe}(\mathrm{II}) / \mathrm{Fe}(\mathrm{III})$ Cycle Promoted Ultra-Highly Sensitive Electrochemical Sensing of Arsenic(III) with Dumbbell-Like Au/ $\mathrm{Fe}_{3} \mathrm{O}_{4}$ Nanoparticles. Anal. Chem. 2018, 90 (7), 45694577.

(34) Zhang, Z.-J.; Wang, Y.-X.; Chou, S.-L.; Li, H.-J.; Liu, H.-K.; Wang, J.-Z. Rapid Synthesis of $\alpha$-Fe2O3/RGO Nanocomposites by Microwave Autoclave as Superior Anodes for Sodium-Ion Batteries. J. Power Sources 2015, 280, 107-113.

(35) Bhattacharya, G.; Fishlock, S. J.; Roy, J. S.; Pritam, A.; Banerjee, D.; Deshmukh, S.; Ghosh, S.; McLaughlin, J. A.; Roy, S. S. Effective Utilization of Waste Red Mud for High Performance Supercapacitor Electrodes. Glob. Challenges 2019, 3 (2), 1800066.

(36) Zhang, J.; Yang, H.; Shen, G.; Cheng, P.; Zhang, J.; Guo, S. Reduction of Graphene Oxide 
1

2

3

4

5

6

7

8

9

10

11

12

13

14

15

16

17

18

19

20

21

22

23

24

25

Vial-Ascorbic Acid. Chem. Commun. 2010, 46 (7), 1112-1114.

(37) Alp, A.; Goral, M. S. The Influence of Soda Additive on the Thermal Properties of Red Mud. J. Therm. Anal. Calorim. 2003, 73 (1), 201-207.

(38) Scheibe, B.; Mrówczyński, R.; Michalak, N.; Załęski, K.; Matczak, M.; Kempiński, M.;

Pietralik, Z.; Lewandowski, M.; Jurga, S.; Stobiecki, F. Anchoring $\mathrm{Fe}_{3} \mathrm{O}_{4}$ Nanoparticles in

a Reduced Graphene Oxide Aerogel Matrix via Polydopamine Coating. Beilstein J. Nanotechnol. 2018, 9, 591-601.

\section{Table of Contents image}

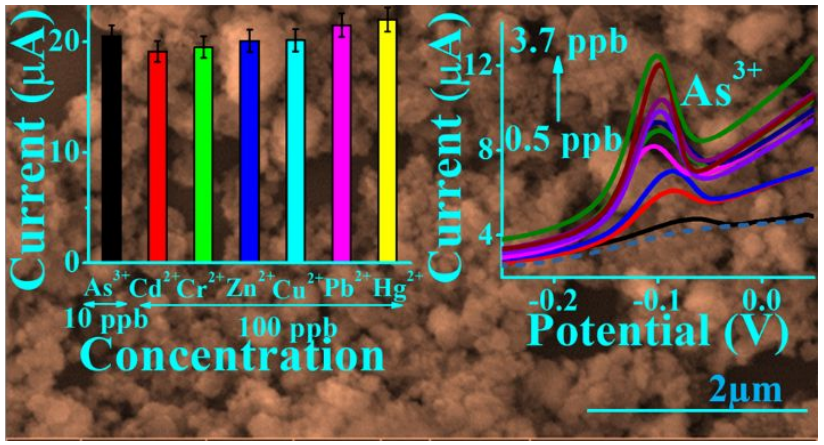

Selective electrochemical detection of $\mathrm{As}^{3+}$ ions using red mud-rGO nanocomposite. 